STCiDioc

Infer, Interpret \& Inspire Science

International Journal of Diabetology \& Vascular Disease Research (IJDVR)

\title{
Inchoate Disaster of Covid-19: A Systematic Review on Risk Factors Triggering Morbidity and Fatality Progression
}

\author{
Research Article
}

Sumit Oberoi ${ }^{1 *}$, Pooja Kansra ${ }^{2}$, Vedica Awasthi ${ }^{3}$, Sugandh Arora ${ }^{4}$

${ }^{1}$ Research Scholar and Corresponding Author, Mittal School of Business, Lovely Professional University, Punjab, India.

${ }^{2}$ Associate Professor, Mittal School of Business, Lovely Professional University, Punjab, India.

${ }^{3}$ Research Scholar, Mittal School of Business, Lovely Professional University, Punjab, India.

${ }^{4}$ Research Scholar, Mittal School of Business, Lovely Professional University, Punjab, India.

\section{Abstract}

Purpose: The global pervasiveness of COVID-19 has been designated as "Public Health Emergency" and it is crafting major health implications globally. Therefore, the aim of the present study is to propose a conceptual model demonstrating risk factors triggering the morbidity and mortality progression in COVID-19 patients.

Method/Design: The present systematic review was carried out in accordance with PRISMA framework. An extensive literature exploration was performed for all published items in numerous databases viz. EBSCO, Google Scholar, ProQuest, Pub-Med and Research Gate. As a result, the inclusion strategy expedited the selection of 28 articles using PICOS procedure. Results: The outcomes of the study suggest that knowledge and awareness regarding risk factors of Covid-19 is momentous for prognostication and prevention. The study delivers an upgraded report in relation to environmental risk factors. Evidence of the rising environmental risks has amplified drastically over the past couple of years and affects the morbidity and comorbidities in grown-ups.

Conclusion: The study clearly elucidates that how various risk factors are directly associated with each other, thereby, leading to the intermediary/susceptible outcomes.

Keywords: Covid-19; Risk Factors; Environmental Risk; Morbidity; Fatality and Systematic Review.

\section{Introduction}

"Coronavirus disease more commonly known as COVID-19 is an infectious disease caused by a newly discovered coronavirus" [37]. The global pervasiveness of COVID-19 has designated the disease with the stature of "Public Health Emergency" and it is acknowledged as the biggest pandemic in human history that doesn't consider any monetary level and ethnic background. According to Lipsitch et al. [19], "The epidemic of 2019 novel coronavirus expanded from Wuhan throughout China and is being exported to a growing number of countries, some of which have seen onward transmission". Preliminary attempts were focused on defining clinical pathways, identifying peracute patients and curing the ailing, but later an imperative need of "public health activities" was encountered to explain the epidemiology of COVID-19 and highlight its risk factors accountable for morbidity and mortality progression.
The pandemic of COVID-19 is crafting major health implications globally. With rising number of severe cases and clinical understandings, a thorough knowledge regarding Covid-19 pandemic has been disseminated. According to Nicola et al. [24] "The upsurge of Covid-19 has been related to the economic scenario of second world war, with detrimental impact on global healthcare systems and ripple effect on all aspects of human life". Supplementary studies from Italy and China elucidated that old age patients diagnosed with diabetes mellitus and other chronic disease, were at greater risk of morbidity and fatality due to Covid-19 $[9,27,38]$. The available literature on associated risk factors of COVID-19 highlights various risk factors in a scattered manner and their impact on COVID-19 patient's morbidity/fatality, the present study aims to propose a conceptual model demonstrating how risk factors collectively trigger the morbidity and fatality

*Corresponding Author:

Sumit Oberoi,

Research Scholar and Corresponding Author, Mittal School of Business, Lovely Professional University, Punjab, India.

Email Id: profsumitoberoi@gmail.com

Received: August 02, 2021

Accepted: October 28, 2021

Published: October 30, 2021

Citation: Sumit Oberoi, Pooja Kansra, Vedica Awasthi, Sugandh Arora. Inchoate Disaster of Covid-19: A Systematic Review on Risk Factors Triggering Morbidity and Fatality Progression. Int J Diabetol Vasc Dis Res. 2021;09(01):270-276. doi: http://dx.doi.org/10.19070/2328-353X-2100051

Copyright: Sumit Oberoi ${ }^{\circ} 2021$. This is an open-access article distributed under the terms of the Creative Commons Attribution License, which permits unrestricted use, distribution and reproduction in any medium, provided the original author and source are credited. 
progression in COVID-19 patients.

\section{Methods And Material}

The present systematic review is accomplished in congruence with "Preferred Reporting Items for Systematic Reviews and Meta-Analysis (PRISMA) framework"” (Moher et al.) [22]. According to Oberoi and Kansra [26], "The article suggests a minimum set of guidelines and procedures of writing items to enhance the quality of the systematic review". An exploration of reliable literature was executed from July 2020 for studies accumulation.

\section{Search Strategy}

An all-embracing literature exploration was performed for all published manuscripts in databases such as EBSCO, Google Scholar, ProQuest, PubMed and Research Gate. Online libraries of the World Health Organization are also searched for more insightful literature. Distinctive search terms were accustomed to different database viz. 'Corona Virus', 'COVID-19', 'Risk Factors', 'Morbidity', 'Mortality', 'Death or Fatality', 'Comorbidities', 'Risk Hazards' and 'Environmental Risks'. Moreover, supplementary studies were explored by searching the backward referencing list or references. After employing the search criteria, 533 articles were exhumed from different-different databases. Thereafter, 367 articles were recognised to be identical and eliminated instantaneously (Figure 1).

\section{Inclusion Strategy}

Of the remaining 166 items, a limited number of studies managed to achieve eligibility criteria grounded upon the "Patient Intervention Comparison Outcome Study" (PICOS) procedure [26]. Further, the remaining 166 articles were evaluated to determine their relevance based on title, abstract and keywords. Only those articles are included which managed to clear the inclusion criteria (a) available in English language; (b) Indexed under Academia, Google Scholar, PubMed, Research Gate, ProQuest and EBSCO; (c) acmes unprecedented research inferences; (d) covering at least one or more risk factor of COVID-19. As a result, the inclusion strategy expedited the selection of 28 articles.

\section{Exclusion Strategy}

A large number of publications were excluded on the following rationales if they (a) doesn't highlight even a single category of the associated risk factors of COVID-19 (behavioural, biological, physical and environmental); (b) published a letter to the editor; (c) were published as research commentaries; (d) non-peer reviewed studies; and (e) were not available in the English language.

\section{Data Extraction and Quality Assessment}

Data extraction and the quality estimation of the available literature was done individually by the authors. In the process of extraction, only those studies were included which highlighted the major risk factors of Covid-19. Microsoft excel spreadsheets are used to document all the essential information. Two distinctive Microsoft excel sheets were developed to summarise the available information. First excel spreadsheet highlights, a predefined profile of the included studies viz. source, year, study type, country, dimensions of risk factors and findings. The second spreadsheet majorly emphasizes the criteria put into practice for quality assessment of included studies. Minors (Methodological index for non-randomized studies) rating scale was adapted for the quality evaluation of the studies. Thus, the quality statements developed were based on the criteria proposed by prior literature [42].

A numerical value of ' 1 ' yes, ' 0.5 ' partially available and ' 0 ' no was allocated to individual quality measure. The included study was considered to be genuinely flawed if it scores less than 5 'Yes'. Hence, all included studies certified the quality evaluation index and hold a low risk of bias selection.

\section{Results}

\section{Study Characteristics}

The characteristics of the twenty-eight included studies were presented in (Table 1). While directing review articles, its indispensable to primarily define the profile of the included studies viz. source, study period (year), study type, location and study

Figure 1. PRISMA Framework for Inclusion Criterion.

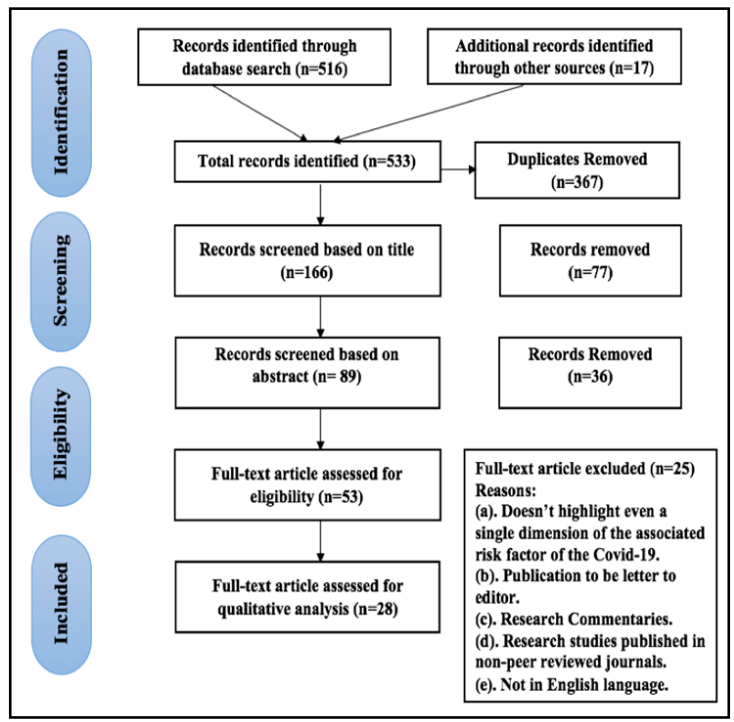


outlook. All included studies were published from January 2020 to July 2020. Of the included 28 studies, 10 studies (35\%) were clinical research, 6 studies $(22 \%)$ were theoretical, 4 studies $(14 \%)$ were empirical and 3 studies (11\%) was categorised under systematic review and review based study type. Lastly, only 2 studies $(7 \%)$ were catalogued under meta-analysis study type. The majority of associated risk factors of Covid-19 was determined from studies published in different countries viz. China ( $\mathrm{n}=11$ studies), U.S.A ( $\mathrm{n}=2$ studies), and one-one study from India, Italy, Romania and the United Kingdom. An enormous percentage of 11 studies $(39 \%)$ were stated under the not available (N.A.) category. Lastly, the findings of the total 28 studies emphasise that biological risk factors were high pointed in the majority of the included studies ( $\mathrm{n}=20$ studies), followed by physical risk factors $(\mathrm{n}=15$ studies), behavioural risk factors ( $\mathrm{n}=8$ studies) and environmental risk factors in 4 studies.

\section{Quality of the Included Studies}

The merits of the reviewed articles are broadly demonstrated in (Table 2). Research questions and study outcomes were elaborately discussed and explained for all 28 included articles. The results of the studies were presented in absolute synchronisation, highlighting the purpose and inferences derived from the manuscripts. It was established that 32 percent $(n=9)$ studies have meticulously outlined the epidemiological explanation of Covid-19. The major limitation witnessed by the large number of studies which restrained the quality of studies was the absence of an extensive elucidation of Covid-19 and dearth of appropriate selection of control group. A large proportion of 13 studies (46 percent) not at all defined Covid-19 and 11 studies (39 percent) partially observed the appropriate selection of control groups.

For the majority of reviewed studies, incorporation of associated risk factors, the relevance of the results to the aim of the article and unbiased assessment of the study conclusion were addressed diligently. However, 79 percent $(n=22)$ of studies coherently outlined the appropriate statistical analysis employed in the review studies and the rest 4 studies partially described the statistical analysis. Henceforth, depending upon the quality scores, a large number of articles $(n=8)$ scored 7 'Yeses' on a 10-point Minors rating scale. Fascinatingly, only 2 research articles highlighted a slightly low score of 5 'Yeses' of the total 28 included research papers as exhibited in (Table 2).

Table 1. Delineation of the included studies.

\begin{tabular}{|c|c|c|c|c|c|}
\hline Ref. No & Source & Year & Study Type & Country & $\begin{array}{c}\text { Type of Risk Factors } \\
\text { Observed }\end{array}$ \\
\hline 1 & Albitar et al., & 2020 & Empirical & N.A. & BioRFs and PRFs \\
\hline 2 & Alqahtani et al., & 2020 & Systematic Review & N.A. & BRFs and BioRFs \\
\hline 6 & Da et al., & 2020 & Empirical & N.A. & BRFs \\
\hline 10 & Hamer et al., & 2020 & Clinical Research & United Kingdom & BRFs \\
\hline 11 & Hou et al., & 2020 & Clinical Research & China & BioRFs and PRFs \\
\hline 12 & Hu et al., & 2020 & Clinical Research & China & BRFs, BioRFs and PRFs \\
\hline 13 & Hussain et al., & 2020 & Systematic Review & N.A. & BioRFs and PRFs \\
\hline 14 & Jin et al., & 2020 & Clinical Research & China & BioRFs and PRFs \\
\hline 15 & Khunti et al., & 2020 & Theoretical & N.A. & BRFs,BioRFs and ERFs \\
\hline 16 & Lakshmi Priyadarsini \& Suresh & 2020 & Narrative Review & India & ERFs \\
\hline 17 & Leung & 2020 & Clinical Research & China & PRFs \\
\hline 18 & Li et al., & 2020 & Clinical Research & China & BioRFs and PRFs \\
\hline 20 & Long et al., & 2020 & Systematic Review & N.A. & BioRFs \\
\hline 21 & Mihai & 2020 & Empirical & Romania & ERFs \\
\hline 23 & Muniyappa\&Gubbi & 2020 & Theoretical & U.S.A & BioRFs and PRFs \\
\hline 27 & Onder et al., & 2020 & Theoretical & Italy & BioRFs and PRFs \\
\hline 28 & Ouchetto\&Bourhanbour & 2020 & Empirical & N.A. & BioRFs and PRFs \\
\hline 29 & Pareek et al., & 2020 & Theoretical & N.A. & BRFs and BioRFs \\
\hline 30 & Prata et al., & 2020 & Narrative Review & N.A. & ERFs \\
\hline 31 & Sattar et al., & 2020 & Theoretical & N.A. & BRFs, BioRFs and PRFs \\
\hline 32 & Shi et al., & 2020 & Clinical Research & China & BioRFs and PRFs \\
\hline 33 & Shi et al., & 2020 & Clinical Research & China & BioRFs \\
\hline 34 & Sun et al., & 2020 & Clinical Research & China & PRFs \\
\hline 36 & Wang et al., & 2020 & Meta-Analysis & China & BioRFs \\
\hline 39 & Yancy & 2020 & Theoretical & U.S.A & BioRFs and PRFs \\
\hline 40 & Zaim et al., & 2020 & Narrative Review & N.A. & BioRFs \\
\hline 42 & Zheng et al., & 2020 & Meta-Analysis & China & BioRFs and PRFs \\
\hline 43 & Zhou et al., & 2020 & Clinical Research & China & BRFs, BioRFs and PRFs \\
\hline
\end{tabular}

Source: Based on authors compilation

Note: N.A. (Not Available); $n=$ number of studies.

BioRFs = Biological Risk Factors; BRFs = Behavioural Risk Factors; ERFs = Environmental Risk Factors and PRFs $=$ Physical Risk Factors 
Table 2. Quality Index of the Included Studies.

\begin{tabular}{|c|c|c|c|c|c|c|c|c|c|c|c|c|c|c|c|c|c|c|c|c|c|c|c|c|c|c|c|c|c|c|}
\hline References & & & & & & & & & & & & & & & & & & & & & & & & & & & & & & \\
\hline Statements & 1 & 2 & 6 & 10 & 11 & 12 & 13 & 14 & 15 & 16 & 17 & 18 & 20 & 21 & 23 & 27 & 28 & & 29 & 30 & 31 & 32 & 33 & 3 & & 36 & 39 & 40 & 42 & 43 \\
\hline $\begin{array}{l}\text { 1. A thorough } \\
\text { definition of } \\
\text { Covid-19 was } \\
\text { given? }\end{array}$ & 0 & 1 & 0.5 & 0 & 1 & 1 & 0.5 & 0 & 0 & 0.5 & 1 & 0 & 1 & 0 & 1 & 0 & 0.5 & & 0 & 0 & 0 & 1 & 0 & 1 & & 0.5 & 0 & 0.5 & 1 & 0 \\
\hline $\begin{array}{l}\text { 2. Aim and ob- } \\
\text { jectives lucidly } \\
\text { defined? }\end{array}$ & 1 & 1 & 1 & 1 & 1 & 1 & 1 & 1 & 1 & 1 & 1 & 1 & 1 & 1 & 1 & 1 & 1 & & 1 & 1 & 1 & 1 & 1 & 1 & & 1 & 0.5 & 1 & 1 & 1 \\
\hline $\begin{array}{l}\text { 4. Study location } \\
\text { was clearly stated? }\end{array}$ & 0 & 0 & 0 & 1 & 1 & 1 & 0 & 1 & 0 & 1 & 1 & 1 & 0 & 1 & 1 & 1 & 0 & & 0 & 0 & 0 & 1 & 1 & 1 & & 1 & 1 & 0 & 1 & 1 \\
\hline $\begin{array}{c}\text { 5. Results were rel- } \\
\text { evant to the aim } \\
\text { of the article? }\end{array}$ & 1 & 1 & 1 & 1 & 1 & 1 & 1 & 1 & 1 & 1 & 1 & 1 & 1 & 0.5 & 1 & 1 & 1 & & 1 & 0.5 & 1 & 1 & 1 & 1 & & 1 & 1 & 1 & 1 & 1 \\
\hline $\begin{array}{l}\text { 6. Unbiased } \\
\text { assessment of the } \\
\text { study conclusion? }\end{array}$ & 1 & 1 & 1 & 1 & 1 & 1 & 1 & 1 & 1 & 1 & 1 & 1 & 1 & 1 & 1 & 1 & 1 & & 1 & 1 & 1 & 1 & 1 & 1 & & 1 & 1 & 1 & 1 & 1 \\
\hline $\begin{array}{c}\text { 7. Follow-up } \\
\text { period appropriate } \\
\text { to the aim of the } \\
\text { study? }\end{array}$ & 1 & 0.5 & 0.5 & 0.5 & 1 & 0.5 & 1 & 0.5 & 0.5 & 1 & 1 & 1 & 0.5 & 1 & 0.5 & 0 & 1 & & 1 & 1 & 0.5 & 1 & 1 & 1 & & 1 & 1 & 0 & 1 & 1 \\
\hline $\begin{array}{l}\text { 8. Appropriate se- } \\
\text { lection of control } \\
\text { group? }\end{array}$ & 0.5 & 0.5 & 0 & 1 & 0.5 & 1 & 0.5 & 0.5 & 0 & 0 & 0 & 1 & 0 & 0.5 & 0.5 & 0 & 0 & & 0 & 0 & 0 & 1 & 0.5 & 0. & & 0 & 0 & 0 & 0.5 & 0.5 \\
\hline $\begin{array}{c}\text { 9. Appropriate } \\
\text { statistical analysis? }\end{array}$ & 1 & 1 & 1 & 1 & 1 & 1 & 1 & 1 & 0 & 0 & 0.5 & 1 & 1 & 1 & 1 & 0.5 & 1 & & 1 & 1 & 0.5 & 1 & 1 & 1 & & 1 & 0.5 & 1 & 1 & 1 \\
\hline $\begin{array}{l}10 . \text { Study Out- } \\
\text { comes were elabo- } \\
\text { rately discussed? }\end{array}$ & 1 & 1 & 1 & 1 & 1 & 1 & 1 & 1 & 1 & 1 & 1 & 1 & 1 & 1 & 1 & 1 & 1 & & 1 & 1 & 1 & 1 & 1 & 1 & & 1 & 1 & 1 & 1 & 1 \\
\hline \multicolumn{31}{|c|}{ Total Score of the Studies Reviewed } \\
\hline Yes (1) & 7 & 6 & 6 & & 8 & 9 & 9 & 7 & 7 & 5 & & 7 & 8 & 9 & 7 & 7 & 8 & 6 & 7 & 7 & 6 & 5 & 9 & 8 & 9 & 8 & 6 & 6 & 9 & 8 \\
\hline No $(0)$ & 2 & 1 & 2 & & 1 & 0 & 0 & 1 & 1 & 4 & & 2 & 1 & 1 & 2 & 1 & 0 & 3 & 2 & 3 & 3 & 3 & 0 & 1 & 0 & 1 & 2 & 3 & 0 & 1 \\
\hline $\begin{array}{c}\text { Partially Available } \\
(0.5)\end{array}$ & 1 & 3 & 2 & & 1 & 1 & 1 & 2 & 2 & 1 & & 1 & 1 & 0 & 1 & 2 & 2 & 1 & 1 & 0 & 1 & 2 & 1 & 1 & 1 & 1 & 2 & 1 & 1 & 1 \\
\hline
\end{tabular}

Source: Based on authors compilation

\section{Mechanism Linking Risk Factors And Suscepti- ble Outcome}

Knowledge regarding risk factors of Covid-19 is momentous for prognostication and prevention. Therefore, to advance an integrated conceptual model, a meticulous examination of the previous literature on Covid-19 was solicitude. Literature on risk factors of Covid-19 is integrated with a wide range of biological; behavioral, environmental and physical risk factors.

\section{Environmental Risk Factors (ERFs)}

Evidence of the rising environmental jeopardies has augmented drastically over the past couple and affects the morbidity and comorbidities in grown-ups. According to Fabian [8], "public overcrowdedness or urban sprawl is very detrimental and increases the risk of contagious viruses by more than 20 times". In a similar study by Bramley et al. [5], a dense locality increases the disorders and encourages unhealthy behaviour. Since, the world is fighting to contain the outspread of COVID-19, the bigger concern for government and hospitals is the mounting medical waste. According to Mihai [21], "Medical and municipal waste management systems are critical services in combating the virus spread in the community". In a similar study by Prata et al. [30], "Mismanagement of personal protective equipment (PPE) during the COVID-19 pandemic, is resulting in widespread environmental contamination. This poses a risk to public health as waste is a vector for $S A R S$ CoV-2 virus". Therefore, inappropriate waste treatment practices and medical waste flow may escalate the risk of contamination. Only a few articles have evaluated the effects of health accessibility as a risk factor for morbidity. Proximity to better health services is a boon for individual/household. According to BooneHeinone et al. [4], "Health conscious individuals, choose to live in areas with better access to health services and healthy food resources". Therefore, individuals living in areas with a lack of approachability to health services are more susceptible to morbidities and illness. Though there is a paucity of literature highlighting the effects of area conditions on rising susceptibility to other major risk factors. According to Zhao et al. [41], Residential proximity to streets or highways is associated with upsurge risk factors viz. obesity, increasing age, lack of exercise, etc.In a similar study by Dendup et al. [7], area conditions and other environmental risk factors are associated with behavioral and physical risk factors viz. physical inactivity, unhealthy diet, stress, etc. thereby, leading to the intermediary outcome of diabetes, hypertension and obesity. Finally, Priyadarsini\& Suresh [16], "identified environmental risk factors, based on their interdependence categorized the triggering factors, air temperature, humidity, airflow and ventilation, responsible for the increased mortality rate of COVID 19".

Preposition 1: - Environmental Risk Factors (ERFs) are directly related to behavioral and physical risk factors which in turn leads to morbidity and fatality amongst Covid-19 patients.

\section{Behavioural Risk Factors (BRFs)}

Several lifestyle habits and behaviours which exert strong consequences on wellbeing are identified as behavioural risk factors 
(BRFs). Behavioral risk factors viz. tobacco use, low servings of fruits \& vegetables and alcohol abuse are the known contributors to biological risk factors [3]. According to Hamer et al. [10], " $A n$ unhealthy lifestyle synonymous with an elevated risk of COVID-19 hospital admission. The findings of the study bighlight lifestyle factor, smoking and obesity but not heavy alcohol consumption were all related to COVID-19". In a similar study by $\mathrm{Da}$ et al. [6], "Patients with alcohol use disorder (AUD) are at a risk for developing severe COVID-19 infection. Alcohol disrupts both the innate and adaptive immune systems and likely predisposes such patients to COVID-19. Also concurrent smokers with chronic respiratory disease that further predisposes them to COVID-19-related morbidity and mortality". Lastly, a couple of analogous studies concluded lifestyle risk factors viz. low serving of fruit/vegetables, smoking and alcohol use disorder are independent risk factors for the unfavourable outcome of Covid-19 [2, 12, 31].

Preposition 2: - Behavioural Risk Factors (BRFs) are directly related to biological risk factors which in turn leads to unfavourable/ susceptible outcomes of Covid-19.

\section{Physical Risk Factors (PRFs)}

Numerous studies have discussed physical risk factors viz. overweight/obesity, no exercise regime and age as momentous risk factors amongst Covid-19 patients [27, 13, 14, 13, 28, 34, 39]. According to Sun et al. [32], "study identified older/advanced age to be the major risk factor for death amongst the hospitalized Covid-19 patients". In a similar study by Leung [17], concluded older/advanced age to be an independent risk factor and associated with mortality amongst the Covid-19 patients. According to Jin et al. [14], "older patients ( $\geq 65$ years old), were more likely to have a Severe type of COVID-19. The study also found that the percentage of older age $(\geq 65$ years) was much higher in the deceased patients than in the patients who survived". Therefore, a copious amount of literature is available highlighting older age triggers the severity of morbidity and mortality amongst Covid-19 patients. Also, a couple of studies by Sattar et al. [31] and Yancy [39], "accentuated older age, bypertension, diabetes mellitus and obesity as imperative risk factors associated with worse outcomes in Covid-19 patients".

Preposition 3: - Physical Risk Factors (PRFs) are directly related to biological risk factors which in turn leads to unfavourable/susceptible outcomes of Covid-19.

\section{Biological Risk Factors (BioRFs)}

According to Thakur et al. [35], "a blend of both dry and wet chemistry techniques are utilized to measure the biological pro- file of patients and associated risk factors". Biological risk factors viz. diabetes, hypertension, coronary heart disease (CHD) and chronic obstructive pulmonary disease (COPD) are identified to be major biological risk factors (BioRFs) for Covid-19 [14, 15, 18, $20,32]$. Hu et al. [16], identified 27 risk factors to be significantly associated with clinical outcomes, but only 8 were established to be independent risk factors and the results register diabetes, hypertension, obstructive lung disease to be the leading risk factor for morbidity and severity amongst Covid-19 patients. In a similar study by Wang et al. [36], investigated that the incidence of chronic comorbidities increases the risk of Covid-19 patients and the cognizance of these BioRFs is an asset for the clinician and medical supervision. According to Muniyappa \& Gubbi [23], "It is well recognized that the presence of diabetes mellitus, hypertension, and severe increase morbidity and mortality in patients with COVID-19”. Lastly, Albitar et al. [1] and Zhou et al. [43], concluded that "hypertension, diabetes mellitus patients, and comorbidities were the independent risk factors of fatality among COVID-19 patients" and additional alertness is a prerequisite for these risk factors.

Preposition 4:- Biological risk factors (BioRFs) are directly associated with the susceptible outcome of Covid-19 and triggering the severity of morbidity and fatality.

\section{Discussion}

Accelerating cases and far-reaching spread of the Covid-19 is a major worry globally. Till date, the cause and pathogenesis of the Covid-19 remains to be ambiguous and no precise therapeutic has been commended for Covid-19 affliction. Thus, immediate recognition of associated risk factors and critical patients is utmost important for strengthening the therapeutic consequences of Covid-19 and plummeting the mortality rate. The principal objective of this study is to identify and seize the proof from available literature on the associated risk factors of Covid-19 which are accessible and published in 2020 . Of the total 533 reports, 28 studies were acknowledged to meet the inclusion criteria. Hence, the outcomes of the study suggest that knowledge and awareness regarding risk factors of Covid-19 is momentous for prognostication and prevention.

Previous literature has explained the presence of usual and standard risk factors viz. behavioural, physical and biological risk factors are associated with Covid-19 patients. To the best of our acquaintance, the present study is the first of its kind to consolidate and propose a conceptual model to demonstrate how environ-

Figure 2. Schematic illustration of conceptual model.

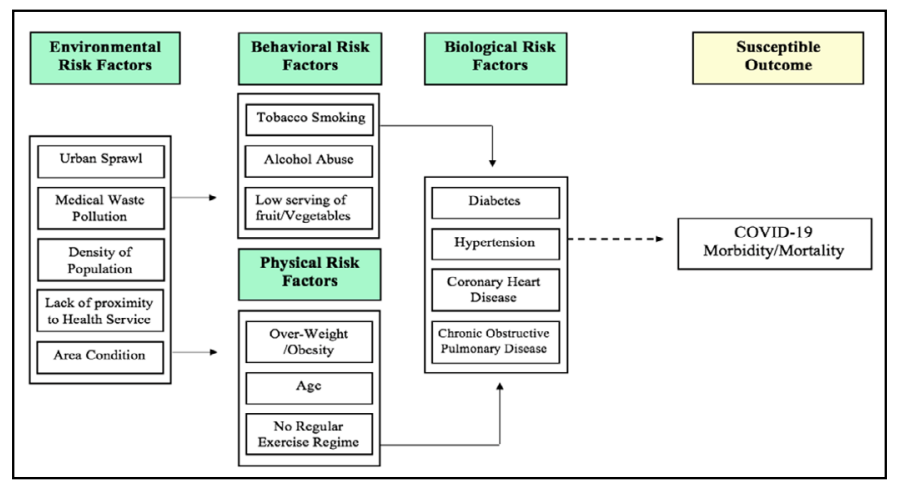


mental, behavioural, physical and biological risk factors collectively trigger the morbidity and mortality progression of COVID-19 patients. The study delivers an upgraded report in relation to environmental risk factors. Evidence of the rising environmental risks has amplified drastically over the past couple of years and affects the morbidity and comorbidities in grown-ups. The findings of the present study are coherent with Dendup et al. [7], environmental risk factors are directly associated with behavioral and physical risk factors viz. physical inactivity, unhealthy diet, stress, etc. thereby, leading to the intermediary/susceptible outcomes.

Taking into the consideration the quality of statistical analysis employed by studies, a substantial amount of 79 percent $(n=22)$ of studies coherently outlined the standard of tools and statistical analysis techniques. Similarly, incorporation of associated risk factors of Covid-19 was also determined by copious amount of assessed articles. The dearth of a thorough definition of Covid-19 and selection of control group generate enigma regarding the quality/standard of the study.

\section{Research Limitations}

The study is approached to the theoretical model and systematically investigation of the prior literature to identify the various types of risk factors collectively triggering the morbidity/mortality of Covid-19 patients. The present study possesses sporadic limitations or restraints. Firstly, the exclusion/elimination of the published articles available as letters to the editors, research commentaries and studies published under non-peer-reviewed journals. With the exclusion of such literature, an essence of biasness might have been commenced in the review process. A deceptive restraint of the present study is the non-existence of the contributions based on empirical data. The future research should empirically validate the conceptual model or perform a meta-analysis using random effect size model.

\section{References}

[1]. Albitar O, Ballouze R, Ooi JP, Ghadzi SM. Risk factors for mortality among COVID-19 patients. Diabetes research and clinical practice. 2020 Aug 1;166:108293.

[2]. Alqahtani JS, Oyelade T, Aldhahir AM, Alghamdi SM, Almehmadi M, Alqahtani AS, et al. Prevalence, severity and mortality associated with COPD and smoking in patients with COVID-19: a rapid systematic review and meta-analysis. PloS one. 2020 May 11;15(5):e0233147.

[3]. Bauer UE, Briss PA, Goodman RA, Bowman BA. Prevention of chronic disease in the 21 st century: elimination of the leading preventable causes of premature death and disability in the USA. The Lancet. $2014 \mathrm{Jul}$ 5;384(9937):45-52.

[4]. Boone-Heinonen J, Gordon-Larsen P, Guilkey DK, Jacobs Jr DR, Popkin BM. Environment and physical activity dynamics: the role of residential selfselection. Psychology of sport and exercise. 2011 Jan 1;12(1):54-60.

[5]. Bramley G, Dempsey N, Power S, Brown C, Watkins D. Social sustainability and urban form: evidence from five British cities. Environment and planning A. 2009 Sep;41(9):2125-42.

[6]. Da BL, Im GY, Schiano TD. COVID-19 hangover: a rising tide of alcohol use disorder and alcohol-associated liver disease. Hepatology. 2020; 72(3): 1102-1108.

[7]. Dendup T, Feng X, Clingan S, Astell-Burt T. Environmental risk factors for developing type 2 diabetes mellitus: a systematic review. International journal of environmental research and public health. 2018 Jan;15(1):78.

[8]. Fabian D. The impact of the COVID-19 crisis on homelessness. European Public Health Alliance. 2020.

[9]. Guan WJ, Ni ZY, Hu Y, Liang WH, Ou CQ, He JX, et al. Clinical characteristics of coronavirus disease 2019 in China. New England journal of medicine. 2020 Apr 30;382(18):1708-20.

[10]. Hamer M, Kivimäki M, Gale CR, Batty GD. Lifestyle risk factors, inflam- matory mechanisms, and COVID-19 hospitalization: A community-based cohort study of 387,109 adults in UK. Brain, behavior, and immunity. 2020 Jul 1;87:184-7.

[11]. Hou W, Zhang W, Jin R, Liang L, Xu B, Hu Z. Risk factors for disease progression in hospitalized patients with COVID-19: a retrospective cohort study. Infectious Diseases. 2020 Jul 2;52(7):498-505.

[12]. Hu L, Chen S, Fu Y, Gao Z, Long H, Ren HW, et al. Risk factors associated with clinical outcomes in 323 coronavirus disease 2019 (COVID-19) hospitalized patients in Wuhan, China. Clinical infectious diseases. 2020 Oct 15;71(16):2089-98.

[13]. Hussain A, Bhowmik B, do Vale Moreira NC. COVID-19 and diabetes: Knowledge in progress. Diabetes research and clinical practice. $2020 \mathrm{Apr}$ $1 ; 162: 108142$.

[14]. Jin JM, Bai P, He W, Wu F, Liu XF, Han DM, et al. Gender differences in patients with COVID-19: focus on severity and mortality. Frontiers in public health. 2020 Apr 29;8:152.

[15]. Khunti K, Singh AK, Pareek M, Hanif W. Is ethnicity linked to incidence or outcomes of covid-19?

[16]. Lakshmi Priyadarsini S, Suresh M. Factors influencing the epidemiological characteristics of pandemic COVID 19: A TISM approach. International Journal of Healthcare Management. 2020 Apr 2;13(2):89-98.

[17]. Leung C. Risk factors for predicting mortality in elderly patients with COVID-19: a review of clinical data in China. Mechanisms of ageing and development. 2020 Jun 1;188:111255.

[18]. Li X, Xu S, Yu M, Wang K, Tao Y, Zhou Y, et al. Risk factors for severity and mortality in adult COVID-19 inpatients in Wuhan. Journal of Allergy and Clinical Immunology. 2020 Jul 1;146(1):110-8.

[19]. Lipsitch M, Swerdlow DL, Finelli L. Defining the epidemiology of Covid-19-studies needed. New England journal of medicine. 2020 Mar 26;382(13):1194-6.

[20]. Long B, Brady WJ, Koyfman A, Gottlieb M. Cardiovascular complications in COVID-19. The American journal of emergency medicine. $2020 \mathrm{Jul}$ 1;38(7):1504-7.

[21]. Mihai FC. Assessment of COVID-19 waste flows during the emergency state in Romania and related public health and environmental concerns. International Journal of Environmental Research and Public Health. 2020 Jan; 17(15):5439.

[22]. Moher D, Liberati A, Tetzlaff J, Altman DG. Preferred reporting items for systematic reviews and meta-analyses: the PRISMA statement. Int J Surg. 2010 Jan 1;8(5):336-41.

[23]. Muniyappa R, Gubbi S. COVID-19 pandemic, coronaviruses, and diabetes mellitus. American Journal of Physiology-Endocrinology and Metabolism. 2020 May 1;318(5):E736-41.

[24]. Nicola M, Alsafi Z, Sohrabi C, Kerwan A, Al-Jabir A, Iosifidis C, Agha $\mathrm{M}$, Agha R. The socio-economic implications of the coronavirus pandemic (COVID-19): A review. International journal of surgery. 2020 Jun 1;78:185-93.

[25]. Kansra P, Oberoi S. Diabetes Risk Factors and Prevention Strategies: Awareness and Perception of Diabetics in Punjab. Economic \& Political Weekly. 2021; 56(5): 60-64.

[26]. Oberoi S, Kansra P. Economic menace of diabetes in India: a systematic review. International Journal of Diabetes in Developing Countries. 2020 Jun $17: 1-2$.

[27]. Onder G, Rezza G, Brusaferro S. Case-fatality rate and characteristics of patients dying in relation to COVID-19 in Italy. Jama. 2020 May 12;323(18):1775-6.

[28]. Ouchetto O, Bourhanbour AD. Risk Factors for Mortality of COVID-19 Patients. medRxiv. 2020 Jan 1.

[29]. Pareek M, Bangash MN, Pareek N, Pan D, Sze S, Minhas JS, et al. Ethnicity and COVID-19: an urgent public health research priority. The Lancet. 2020 May 2;395(10234):1421-2.

[30]. Prata JC, Silva AL, Walker TR, Duarte AC, Rocha-Santos T. COVID-19 pandemic repercussions on the use and management of plastics. Environmental Science \& Technology. 2020 Jun 12;54(13):7760-5.

[31]. Sattar N, McInnes IB, McMurray JJ. Obesity is a risk factor for severe COVID-19 infection: multiple potential mechanisms. Circulation. $2020 \mathrm{Jul}$ 7;142(1):4-6

[32]. Shi S, Qin M, Shen B, Cai Y, Liu T, Yang F, et al. Association of cardiac injury with mortality in hospitalized patients with COVID-19 in Wuhan, China. JAMA cardiology. 2020 Jul 1;5(7):802-10.

[33]. Shi Y, Yu X, Zhao H, Wang H, Zhao R, Sheng J. Host susceptibility to severe COVID-19 and establishment of a host risk score: findings of 487 cases outside Wuhan. Critical care. 2020 Dec;24(1):1-4.

[34]. Sun H, Ning R, Tao Y, Yu C, Deng X, Zhao C, et al. Risk factors for mortality in 244 older adults with COVID-19 in Wuhan, China: a retrospective study. Journal of the American Geriatrics Society. 2020 Jun;68(6):E19-23.

[35]. Thakur JS, Jeet G, Pal A, Singh S, Singh A, Deepti SS, et al. Profile of risk 
factors for non-communicable diseases in Punjab, Northern India: Results of a state-wide STEPS survey. PLoS One. 2016 Jul 7;11(7):e0157705.

[36]. Wang B, Li R, Lu Z, Huang Y. Does comorbidity increase the risk of patients with COVID-19: evidence from meta-analysis. Aging (Albany NY). 2020 Apr 15;12(7):6049.

[37]. World Health Organization. Coronavirus. 2020.

[38]. Wu Z, McGoogan JM. Characteristics of and important lessons from the coronavirus disease 2019 (COVID-19) outbreak in China: summary of a report of 72314 cases from the Chinese Center for Disease Control and Prevention. Jama. 2020 Apr 7;323(13):1239-42.

[39]. Yancy CW. COVID-19 and african americans. Jama. 2020 May 19;323(19):1891-2.
[40]. Zaim S, Chong JH, Sankaranarayanan V, Harky A. COVID-19 and multiorgan response. Current Problems in Cardiology. 2020: 100618.

[41]. Zhao Z, Lin F, Wang B, Cao Y, Hou X, Wang Y. Residential proximity to major roadways and risk of type 2 diabetes mellitus: a meta-analysis. International journal of environmental research and public health. 2017 Jan;14(1):3.

[42]. Zheng Z, Peng F, Xu B, Zhao J, Liu H, Peng J, et al. Risk factors of critical \& mortal COVID-19 cases: A systematic literature review and meta-analysis. Journal of infection. 2020 Aug 1;81(2):e16-25.

[43]. Zhou F, Yu T, Du R, Fan G, Liu Y, Liu Z, et al. Clinical course and risk factors for mortality of adult in patients with COVID-19 in Wuhan, China: a retrospective cohort study. The lancet. 2020 Mar 28;395(10229):1054-62. 